\title{
Fiscaoeconomia
}

\section{Subtleties in the Standoff}

\section{Amelia CORREA ${ }^{\mathbf{1}}$, Romar CORREA ${ }^{2}$}

\section{ARTICLE INFO}

Article History:

Date Submitted: 20.06.2017

Date Accepted: 17.01.2018

JEL Classification:

E12

E58

E61

Keywords:

A Quantity Trap.

\begin{abstract}
We reflect on the issues raised by the recent faceoff between the Reserve Bank of India (RBI) and the Indian government over the short-term interest rate. Our conclusion is that the policy space must be enlarged and the set of outcomes specified in order for meaningful dialogue to be conducted between the two entities.
\end{abstract}

\footnotetext{
${ }^{1}$ Department of Economics, St Andrew’s College, University of Mumbai, India email: ameliacor@gmail.com

2 retired Reserve Bank of India Professor, University of Mumbai, India email: romarcorrea10@gmail.com
} 


\section{Introduction}

Anywhere in the world but highlighted by the drama surrounding policy pronouncements in the US, the bone of contention between the central bank of the country and the central government is the short-term rate of interest. The latter would prefer a downward movement, particularly in a recession, so that firms can have access to cheap(er) credit. Even at this point in the transmission mechanism the possibility that firms might avail of credit so as to intervene in the financial circuit rather than employ workers and produce goods and services is not entertained. The task of central bankers is much easier in that they must only target an inflation rate using a formula like a Taylor rule. The more intransigent they are the greater their credibility and reputation, at least in financial markets.

In India, the stubbornness of the Governor(s) of the RBI has begun to incur the public disapproval of the government. We offer a general treatment of the issues raised. The target audience is students of introductory economics who are likely to be swayed by the rhetoric of one or the other. Accordingly, we have selected a book cheaply and easily accessed in (Indian) markets and one we have had repeated recourse to as teachers (Michl, 2009). Our notations and treatment will follow closely in the tracks of the book to facilitate easy education.

\section{Macro 101}

The discussion surrounding transparency and disclosure in the Indian policy context is muddied by the absence of an explicit model or models within which debate might be conducted. At best, there are reflex responses following from potted wisdom about central bank autonomy, balancing of budgets, allowing the private sector to flower fully, and so on. While the Governor of the RBI Urjit Patel (UP) remains relatively reticent, the Chief Economic Advisor to the Government of India Arvind Subramaniam (AS) has been vocal on themes concerning the connection between the short-term interest rate and activity, about what the optimal inflation rate must be, and so on. His speeches and interviews provide a convenient starting point. In order to provide flavor to the discussion, each policy maker will be identified by a superscript. 
Plunging straight into the heart of the matter, we have the "central bank reaction function" (Michl, 156).

$$
r=h_{0}+h_{1} \pi-h_{2} u
$$

Here $r$ is the real interest rate, $\pi$ is the inflation rate, $u$ is the unemployment rate which is defined as $u=\frac{L-N}{L}$ where $L$ is the labour force, assumed constant in the period under discussion, and $N$ is labour units. The aggregate production function is $Y=N$.

In a 'personification' of the Theil-Tinbergen rule, a bureaucrat cannot join the Governor of a central bank in controlling the left-hand side. As already noted, the orientation of one will be upward with a higher weight on the inflation target, the other predisposed to lower the overnight rate in the interest of reducing unemployment. Thus even in an amalgam of the monetary and fiscal authorities, foregoing autonomy of the central bank, the problem is intractable. In order to present the dilemma sharply, we break up the policy reaction function to include a 'fiscal authorities' reaction function'. We separate the inflation and unemployment objectives, the former being under the care of the central bank and the latter under the supervision of the fiscal authorities.

$$
\begin{aligned}
& r^{U P}=h_{0}+h_{1} \pi \\
& r^{A S}=h_{0}-h_{2} u
\end{aligned}
$$

In the picture below, the reaction function (RF) of the fiscal authorities is convex in inflation-unemployment space, that of the monetary authorities is concave. 


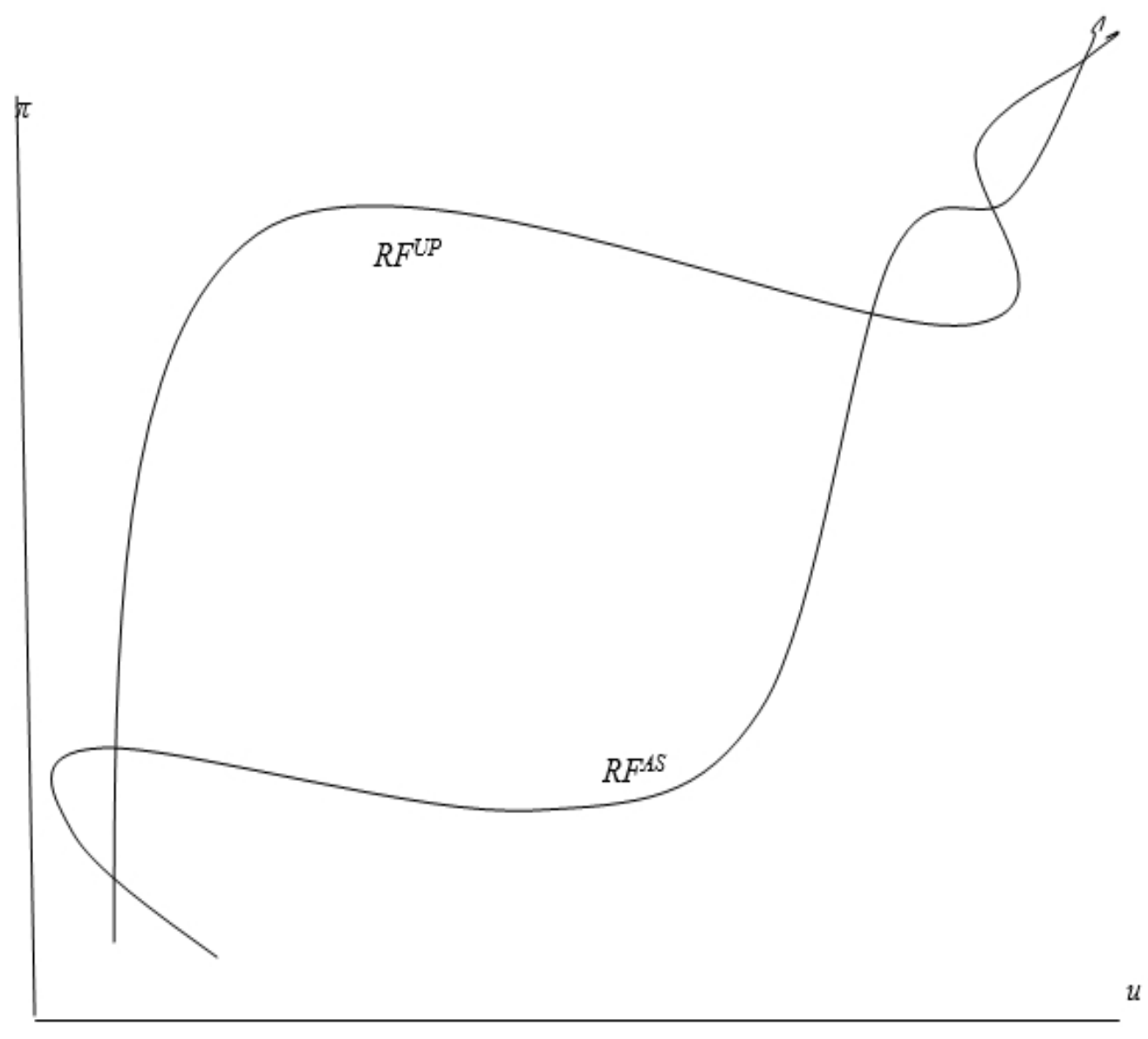

\section{Diagram 1}

The positive slopes of both curves at the higher and lower ends of the spectrum are meant to signify that near the origin, both parties would welcome some inflation in the interest of 'greasing the wheels of commerce'. Similarly, at the other end both government and central bank would be concerned about an inflationary spiral and would settle for a lower level of activity. In other words, there are multiple equilibria at both tails. Furthermore, the economy is strictly worse off if coordination between the authorities takes place on the upper end of the graph. The essential point here is that for the vast body of policy space there is no détente. To repeat the Theil-Tinbergen formula: we are one instrument short. Our contribution is via IS-LM before being combined into an aggregate demand curve. "Deriving the IS curve" we reproduce the following (Michl, 52-53). All we add is an income tax rate theta. With $T$ a 
lump-sum tax on all households, $T=\theta Y$, and with $i$ the nominal interest rate the linear consumption and investment functions are

$$
\begin{aligned}
& C=c_{0}+c_{1}(Y-T) \\
& I=b_{0}+b_{1} Y-b_{2} i
\end{aligned}
$$

With $Z$ standing for aggregate demand, equilibrium in the commodities market, $Z=Y$, gives

$$
Y=\frac{c_{0}+b_{0}}{1-c_{1}+\theta c_{1}-b_{1}}+\frac{G}{1-c_{1}+\theta c_{1}-b_{1}}-\frac{b_{2}}{1-c_{1}+\theta c_{1}-b_{1}} i
$$

Using the consolidating parameter advised,

$$
Y=\gamma\left(c_{0}+b_{0}\right)+\gamma G-\gamma b_{2} i
$$

More simply,

$$
Y=a_{0}+a_{1} G-a_{2} i
$$

Output and government expenditure (and fiscal policy more generally through the multiplier) are taken as endogenous. Intersection between the IS and the LM curve below will not be sought in the interest of distinguishing between monetary and fiscal policy. Instead, we opt for the steady-state values of the primary identities and the attendant "fiscal stance" (Godley \& Cripps, 1983, 111). It is the case of budget balance, income tax revenues equal government expenditures. Thus, $G^{*}=T=\theta Y^{*}$. We drop this anchor on our curve $G^{U P}$ in our first quadrant below.

The LM curve in the second quadrant is the familiar relationship. With real balances $M / P$ we cut straight through to the curve with consolidating variables (Michl, 69):

$$
i=-a_{3}\left(\frac{M}{P}\right)+a_{4} Y
$$


In the third quadrant we have the Fisher relationship. With $r$ standing for the real rate of interest and $\pi^{e}$ the expected inflation rate, we have (Michl: 156)

$$
i=r+\pi^{e}
$$

Finally, the aggregate supply curve or the Phillips curve is depicted in the fourth quadrant. It is a 'translation' from the $x$-axis of the first quadrant abstracting from $C+I$. With a modification of consolidating parameters for the purpose of expressing the right-hand side in terms of output rather than the familiar unemployment and with mu standing for the degree of monopoly, the equation is (Michl: 132)

$$
\pi=\mu+\beta Y
$$

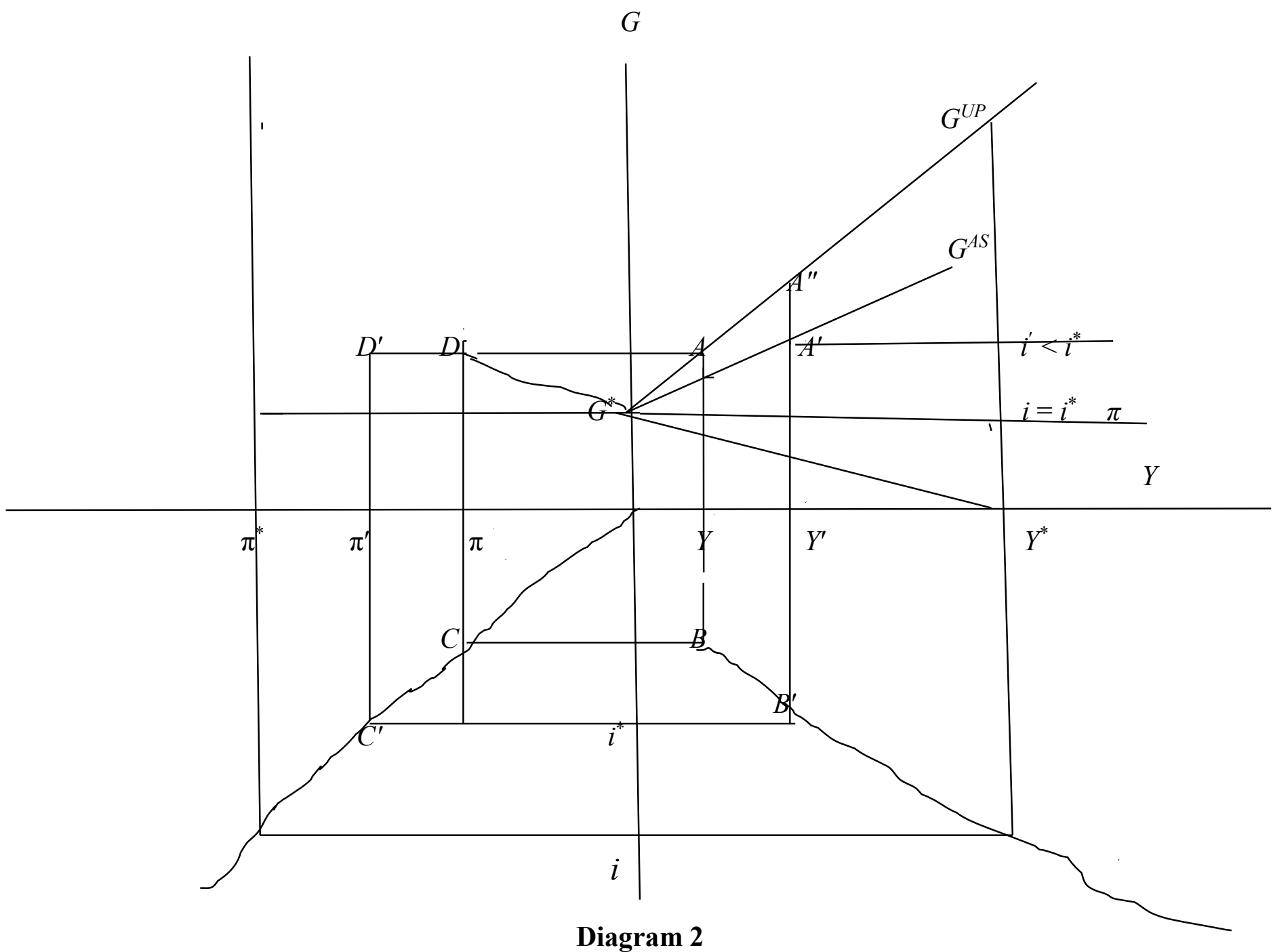


The quadrants can be looked at two ways if desired. The two on the right are the aggregate demand curve, the two on the left the aggregate supply curve. The first and the fourth can be regarded as the real side of the economy, the second and the third the monetary aspects of the model.

\section{The Positions}

The benchmark starred values are only steady-state values not optimal or target values. Indeed, $Y^{*}$ is not the 'maximal' level of output. The position reflects the current reality of the worldwide recession rather than logic. The fluctuations of $Y$ and $Y^{\prime}$ about the steady state can take place at any position of the latter. The $i^{*}$ can be called the steady-state value of the nominal interest rate emerging from the fiscal stance and the starred inflation rate can likewise be so characterized. Now consider the current state of the economy captured by $A B C D$. From the perch of $A$, the government might feel that the situation is unnecessarily confining with a liquidity crunch. A drop in the policy interest rate from $i^{*}$ to $i^{\prime}$ would stimulate investment demand, the new overall equilibrium depicted by primes. The particular charge levied by the government against the RBI is that $\pi$, the inflation rate in the initial condition, is comfortably low and some latitude can be permitted in the move to $\pi^{\prime}$ which still remains far from the steady-state $\pi^{*}$. The bureaucrat can profess a commitment to fiscal rectitude insofar as government expenditure is concerned. The usual route to take is rightward along the $G^{U P}$ curve to a point $A^{\prime \prime}$ directly above $A^{\prime}$ and $Y^{\prime}$.

However, the central bank could as well advise a movement along the existing curve from $A$ to the eventual end point $G^{*}$. The fiscal consolidation programme should be conducted in a credible fashion and following a timetable. Secondly, the reliance on the propensity to invest, $b_{2}$, to see economies home to superior equilibria has usually met with disappointing results. In this epoch of near-zero and negative actual and policy rates and stagnant activity, to expect much from even large basis points reductions in the short-term interest rate must seem foolhardy. The weakness of the interest rate response could carry over to the demand for money. If it is insensitive to that number with a vertical LM curve, even an upward-sloping supply of money function will be of no avail for pushing the economy outward from $Y$. 
Referring to the graph of the familiar taxonomy but now reverting to the other axis, in place of a liquidity trap we have an 'output trap'.

Price stickiness of a different sort applies to the general price level if the origin of our account is the fourth quadrant. The price level and the wage rate are the outcome of the markup and the bargaining strength of the working class. The inflation rate can be lowered by a coordinated climb-down on target price levels by capitalists and workers. Such an outcome would be the fruit of a "social democratic" model which applied to the golden age of capitalist development long past (Bastian \& Setterfield, 2017). During the period 1948-1973, the general spread of universal health and education along with the commitment to full employment led to an implicit contract between the classes. At the heart of such arrangements is the adherence to the macroeconomic identity that wage increases must go hand-in-glove with productivity increases. Contrariwise, workers must be sensitive and proactive with reference to productivity slowdowns. The current dispensation is the widely discredited "neoliberal" model which is the product of the decimation of collective worker class interests worldwide. Long-term contracts have given way to piecework and outsourcing.

\section{Conclusion}

The rate of interest is increasingly being regarded as a slender limb on which to hang the weight of policy machinery. Theorists continue to grapple with the meaning of the natural, the neutral, and other representations of that variable. Current fashion runs in terms of the long rate in notions like forward guidance. Proxies are sought for the purpose of econometric applications. Senior statesmen of the science with feet firmly planted both in theory and empirics have urged an increase in the target inflation rate because the long-term real rate of interest has gone up. The implication is that the nominal rate of interest must go up as well.

In short, the only solution to our problem, given a desired $Y^{\prime}$ is an increase in current government expenditure to the point $A$ ". The 'multiplier' effects of such a move might be novel. Recent work on China has effectively illustrated the role of government intervention in facilitating the accumulation of capital in situations when institutions are unsophisticated and legal and property rights rudimentary $(\mathrm{Fu}, 2017)$. The answer is that governments enter into 
strategic partnerships with banks and firms in devising investment strategies. Rigorous econometric testing in the work referred to has established the causal virtuous loop between government intervention, credit access, and profits. Underlying the relationship is, expectedly, the underwriting of unquantifiable risks.

\section{References}

Bastian, E.F., Setterfield, M. (2017). Nominal Exchange Rate Shocks and Inflation in an Open Economy: Towards a Structuralist Inflation Targeting Agenda, The New School for Social Research Working Paper 20/2017

Fu, T. (2017). What Determines Firm's Credit to Access in the Absence of Effective Economic Institutions: Evidence from China, Economics Discussion Paper 2017.35, Kiel Institute for the World Economy

Godley, W., and Cripps, F. (1983). Macroeconomics, Oxford: Oxford University Press

Michl, T. R. (2009). Macroeconomic Theory, New Delhi: PHI Learning 